\title{
The Geneva Risk and Insurance Review 2010: We Have Learned Much Since Willett and Knight
}

\author{
Jean-François Outreville \\ HEC Montreal, 3000 cote Sainte Catherine, Montreal, Quebec, Canada H3T 2A7. \\ E-mail: j-francois.outreville@hec.ca
}

The purpose of this paper is to review and summarise the papers published in The Geneva Risk and Insurance Review in 2010. Historical reference to Willet and Knight is emphasised to illustrate the importance of risk and uncertainty in our modern economies and how it is still the starting point of economic research not only in public finance as proposed by Agnar Sandmo, but also in other papers published in this volume. Many issues touch upon anomalies like adverse selection, asymmetric information, moral hazard and rating restrictions that can influence the performance of insurance markets. These issues are of particular relevance for insurers and the proper functioning of insurance markets.

The Geneva Papers (2011) 36, 476-487. doi:10.1057/gpp.2011.17

Keywords: risk and uncertainty; asymmetric information; insurance

\section{Introduction}

Regardless of the manner in which risk is defined, its existence affects the economic performance of agents and therefore imposes constraints on the optimum allocation of resources and on the economic development of all nations. Individual as well as business decisions are made under conditions of uncertainty. In 1901, A.H. Willett refers to the costs of uncertainty arising out of (1) the unexpected losses that do occur and (2) the uncertainty itself even if no losses occurs. He also refers to uncertainty as a disutility. The prudent individual response to uncertainty (as to whether a loss will occur) is to engage in safe actions rather than risky ones. At the society level, this behaviour may cause distortions in the optimal allocation of productive resources. "The existence of risk in an approximate static state causes an economic loss. The assumption of risk, on the other hand, is a source of gain to the society as a whole". 1

Although the idea of risk may be difficult to conceptualise, risk is of considerable importance for the functioning of all economies and economic agents. ${ }^{2}$ Frank $\mathrm{H}$. Knight (1885-1972) is usually credited for having presented the distinction between decisions under "risk" (known chance) and decisions under "uncertainty" in his 1921 book. ${ }^{3}$ It is interesting to note that Knight defined profit as a reward for assuming risk

\footnotetext{
${ }^{1}$ Willett (1901, p. 32).

${ }^{2}$ Bernstein (1998) walks that path. Against the Gods follows the intellectual development of risk management and how people throughout the centuries have changed their views of what constitutes risk and how risk can be mitigated. See also Outreville (1998, Chapter 2).

${ }^{3}$ Knight (1921).
} 
and claimed that only uncertainties create an economic problem. ${ }^{4}$ The convention in finance is to interpret risk in the spirit of Willet and Knight. ${ }^{5}$

The remarkable story of risk and uncertainty touches on the most profound aspects of psychology, mathematics and statistics. Knight discussed several biases in human decision-making and described features of risky choice (a function of anticipatory futures) that were to become key components of prospect theory. ${ }^{6}$ The basic principle of insurance is also described at length by Knight: "risks will be borne in groups large enough to reduce the uncertainty to substantially negligible proportions", but at the same time he recognises that "practical difficulties may prevent insurance even where the risk is determinate". ${ }^{7}$ LeRoy and Singell ${ }^{8}$ produced an interpretation on the distinction made by Knight between situations in which insurance markets can operate smoothly (risk) and situations in which insurance markets would collapse because of moral hazard and adverse selection (uncertainty).

The conceptual link between insurance and risk-with risk being a calculable subset within a larger set of uncertainties - has been subject to a fair amount of study in the literature. Recent sociological and historical work by Ericson and Doyle ${ }^{9}$ has explained how insurance risks very often are not reliably calculable, although the risk has already been transformed into an all-too-measurable loss. Insurance is an "uncertain business", characterised by competition for premiums that pushes insurers into the unknown and the performance of insurance market is affected by the presence of anomalies that may affect the risk-taking behaviour of agents and the optimal allocation of insurance in the economy. ${ }^{10}$

In light of this background, the purpose of this paper is to review and summarise the papers published in The Geneva Risk and Insurance Review (GRIR) in 2010. This volume of the $G R I R$ is particularly important, not only because it includes a paper by Agnar Sandmo, ${ }^{11}$ who discusses the role that the economics of uncertainty has played in the theory of public finance, but also because several papers touch upon the anomalies that can influence the performance of insurance markets. A paper examines premium cross-subsidies and how it affects the risk-taking behaviour of agents. Other papers are looking at issues such as the relationship between risk and coverage under adverse selection, the probability distributions of risks or wealth effects on self-insurance when an unfair premium encourages risk-averse individuals to purchase a partial coverage of insurance.

\footnotetext{
${ }^{4}$ See Brooke (2010) for a discussion on the contribution of Frank Knight.

${ }^{5}$ For a different point of view, see Holton (2004).

${ }^{6}$ See Rakow (2010) for a discussion on the psychological insights of Frank Knight. Knight (1935) developed the idea in The Ethics of Competition: "The first question in regard to scientific economics is this question of how far life is rational, how far its problems reduce to the form of using given means to achieve given ends".

${ }^{7}$ Knight (1921, Chapter 2, Part I).

${ }^{8}$ Le Roy and Singell (1987).

${ }^{9}$ Ericson and Doyle (2004).

${ }^{10}$ Eeckhoudt et al. (2005, Chapter 3).

${ }^{11}$ Sandmo (2010).
} 
The following sections of this paper present an overview of the major topics explored in eight papers published in GRIR 2010. The last section will summarise the results and brief remarks conclude the paper.

\section{Uncertainty in the theory of public finance}

In 1713 , the basis of the modern mathematical probability theory developed by Jacob Bernoulli in "Ars Conjectandi" is published (eight years after his death) in Basel. In 1738, Daniel Bernoulli published his answer to the game known as the "St. Petersburg paradox". In his approach, he suggested that the outcome of a lottery should be valued according to the "expected utility (EU)" that it provides rather than the mathematical expectation. ${ }^{12}$ It is surprising that economists did not apply the ideas of Bernoulli on risk aversion and EU before it had been proved as a theorem by Von Neuman and Mortgenstern in 1947. Karl Borch relates the lack of interest of Walras or Marshall to the Daniel Bernoulli principle and its implications in his late book. ${ }^{13}$

As explained by Agnar Sandmo, ${ }^{14}$ although there was a lack of interest for the economics of uncertainty in the early 1960s, the theory of EU maximisation and the concept of risk aversion have contributed decisively to the development of several areas of the theory of public finance. To illustrate the point, this paper discusses the role of uncertainty in public expenditure analysis and in the theory of tax evasion.

The concavity of the relationship between wealth and satisfaction/utility is quite a natural assumption. It is also intuitive that a decreasing marginal utility means risk aversion. Over the last two decades, this relationship has been challenged by many. ${ }^{12}$ Clearly, people have different attitudes towards risks, but when it comes to the analysis of uncertainty and public expenditure, there are two aspects of the basic theories where formal concepts in the economics of uncertainty could be applied. One is the question by A. Sandmo of how public expenditure affects private decisions regarding risk taking; the other is the issue of the optimal supply of public goods when costs or benefits are uncertain.

According to the theory and making the reasonable assumption that absolute risk aversion is decreasing, the author explains how an increase in the supply of public goods (or publicly provided goods) increases the willingness to take risks, as it is equivalent to an increase in initial wealth. But as public goods are budgeted through taxes, does taxation deter or encourage risk taking?

Although some views tend to suggest that the effect of taxation is negative, primarily because of the adverse effect on the volume of saving, the author relies on previous work by Domar and Musgrave ${ }^{15}$ (before any reference to EU functions) and others (within the EU framework) to show that the effect is likely to go in the direction of more risk taking. The result is apparently independent of the shape of the utility

\footnotetext{
${ }^{12}$ See Eeckhoudt et al. (2005, Chapter 1).

${ }^{13}$ Borch (1990, p. 6).

${ }^{14}$ Sandmo (2010, p. 1).

${ }^{15}$ Domar and Musgrave (1944).
} 
function, but only apparently as the initial allocation of wealth between safe and risky assets depends on the shape of the utility function. The author therefore concludes that the result that capital income taxation tends to encourage risk taking is in the nature of an empirical hypothesis.

Taking into account the effects of income taxation and public expenditure on private risk taking, it is hard to avoid the conclusion that a government that taxes private risky investments and uses the revenue to provide public goods encourages private risk-taking behaviour. Through taxation of risky returns with loss offset, it provides insurance, and through the provision of "welfare goods", it creates a social safety net. ${ }^{16}$

The analysis of tax evasion is also interesting in this context. The economic agent faces the decision to report his income to the government tax collector. The author considers that the amount that he chooses to report is the equivalent of the safe asset and the amount that he does not report corresponds to the risky asset. It seems reasonable to assume that a higher gross income will increase evasion if one believes that people become more willing to engage in risky activities as they get richer. This is also predicted by the model if one makes the additional assumption of decreasing absolute risk aversion (DARA).

The author shows that as long as the regular tax rate is less than the expected penalty rate, the taxpayer will not engage in any tax evasion. In most countries, this relationship is reversed and tax evasion according to the theory is certainly much more widespread than empirical studies indicate that it is. But as the author explains, there are many additional considerations to take into account regarding the effects of tax evasion and some questions of a more fundamental nature remains for normative economics.

\section{More on risk aversion}

One way to measure the degree of risk aversion of an agent is to ask how much he/she is ready to pay to avoid of a zero-mean risk. The answer to this question is called the risk premium associated with that risk. ${ }^{12}$ In many cases, the risk premium associated with any large risk will also depend on the moments of the distribution of the risk, not just the mean and variance. For example, it seems intuitive that the degree of skewness - the third moment - might well affect the desirability of a risk. A similar argument can be made about the kurtosis - the fourth moment — which is linked to the probability mass in the tails of the distribution.

The paper by $\mathrm{Chiu}^{17}$ looks at empirical evidence on skewness preference. Mean-variance decision models are consistent with EU maximisation, but preference for a larger third moment is in general not consistent with EU maximisation. The author establishes a skewness-comparability condition on probability distributions that is necessary and sufficient for any decision-maker's preferences over the distributions to depend on the first three moments of the distributions. Utility

\footnotetext{
${ }^{16}$ Sandmo (2010, p. 9).

${ }^{17}$ Chiu (2010).
} 
maximiser's preferences for a larger mean, a smaller variance and a larger third moment are shown to be understood as trade-offs.

Available empirical evidence suggests that skewness preference plays an important role in understanding asset pricing (this was already anticipated by Markowitz) and gambling. It is possible for an individual who is averse to larger variances, as is usually assumed in the context of mean-variance analysis, to accept an independent fair gamble given a sufficiently strong skewness preference. The author illustrates his point by giving examples in the understanding of individuals' betting behaviour and self-protection decisions. The same approach can also be applied to analyse the effects that progressive tax reforms could have on the willingness to take risk compared with a proportional income tax. Such a reform increases the skewness of the after-tax income distribution and as a result, other things being equal, enhances the incentive to make risky investments.

Within an expected-utility framework, decision-makers are usually assumed to be non-satiated and risk averse. In contrast to ordinal utility, the sign of every derivative of the von Neumann-Morgenstern utility function $U$ has some economic meaning. As the work of Pratt ${ }^{18}$ and Arrow, ${ }^{19}$ it has been recognised that the ratio- $U^{\prime \prime} / U^{\prime}$ (the so-called Absolute Risk Aversion) is an appropriate measure of degree of risk aversion. More recently, it has been shown that higher-order derivatives of $U$ also matter. A large body of literature on implications of higher-order risk preference has emerged. The notions of prudence and temperance have since been defined by the sign of the third and fourth derivative of the utility function, $U^{\prime \prime \prime}>0$ and $U^{\prime \prime \prime \prime}<0$, respectively. ${ }^{20}$

Prudence has been shown to be equivalent to aversion to an increase in downside risk as defined by Menezes and others. ${ }^{21}$ A downside risk does not change mean and variance of a prospect but does increase its skewness. Likewise with kurtosis related to temperance. In the literature, an individual is said to be prudent if adding a zero-mean risk to his future income raises his optimal saving. When comparing two lotteries whose distributions have the same first two moments, a prudent person prefers the lottery where the distribution is right skewed (positive skewness) compared with the lottery that is left skewed (negative skewness). Although investors are concerned foremost with mean and variance, they are also sensitive to downside risk. Prudence has been shown theoretically to be an important determinant of precautionary savings, asset allocation and optimal prevention levels. ${ }^{22}$ In a note on risk aversion, prudence and portfolio insurance, Bertrand and Prigent ${ }^{23}$ provide explicit conditions to measure portfolio sensitivity to downside risk.

\footnotetext{
18 Pratt (1964).

19 Arrow (1965).

${ }^{20}$ See, for example, Eeckhoudt et al. (1995) or more recently Eeckhoudt and Schlesinger (2006).

${ }^{21}$ An increase of skewness will imply an increase in downside risk only under specific conditions (Chiu, 2005; Menezes et al., 1980).

${ }^{22}$ Kimball (1990) introduces the notion of prudence within the expected-utility framework. He shows that prudence corresponds to a precautionary-savings motive.

23 Bertrand and Prigent (2010).
} 
The portfolio optimisation theory usually considers that investors maximise the EU of portfolio values which may be payoff functions of a given reference index or benchmark. The focus is not only on losses (like insurance) but also on potential gains. Looking at the relationship between risk aversion and prudence on the one hand and at optimal portfolio payoff on the other hand, the authors demonstrate that the ratio of absolute prudence to absolute risk aversion (cautiousness is equal to the ratio of prudence to risk aversion minus one $)^{24}$ plays a key role in explaining the investor's portfolio position in a risky asset. It is the investor's propension to risk in order to benefit from financial market rises. The optimal payoff of any prudent investor has always less downside risk than any other payoff.

An investor's decisions on precautionary saving and investment in equity must be closely related, and prudence must be closely associated with risk aversion. ${ }^{25}$ The concepts risk aversion, prudence and cautiousness have interpretations for investor's main activities in financial markets, namely investment, saving and hedging, respectively. ${ }^{26}$ The relationships between these concepts reveal that a more absolutely prudent investor is almost naturally more absolutely risk averse, parallel to Kimball's finding that decreasing absolute prudence implies DARA.

The most persuasive hypothesis that has come to be widely accepted in the literature, because it is consistent with intuition and empirical observation, is DARA. DARA means equivalently that an investor's risk premium is a decreasing function of his wealth for any certain level of risk and this assumption of decreasing absolute risk aversion is equivalent to the coefficient of prudence. The link between prudence and self-protection activities in the terminology of Ehrlich and Becker ${ }^{27}$ has also been recently studied to show the relationship between prudence, decreasing risk aversion and self-protection. ${ }^{28}$

Under DARA, the known result is that insurance is an inferior good. This is intuitive as, with an unfair premium, risk-averse individuals purchase a partial coverage of insurance, exposing them to random loss. The paper by Lee ${ }^{29}$ in Volume 2 of the GRIR considers the effect of DARA on self-insurance investment that reduces loss. It claims that self-insurance has been associated wrongly to a type of insurance and that the general results on insurance are carry over to self-insurance.

This paper studies the wealth effects on self-insurance with a two-loss states framework, as usual, but also in multiple states of the world, and demonstrates that self-insurance may be either a normal good or an inferior good. Under DARA, wealthier individuals are less risk averse and therefore purchase less insurance coverage. However, there is no à priori reason that the conditions that are considered

\footnotetext{
${ }^{24}$ Leland (1980) suggested using this measure to explain convexity of investors' optimal payoff functions, which is related to the feature of options. Huang (2000) established that cautiousness is a measure of investors' tendencies to buy options.

${ }^{25}$ See Eeckhoudt and Schlesinger (1994).

${ }^{26}$ Lajeria and Nielsen (2000) provide parametric characterisations of risk aversion and prudence, two concepts that play an important role in the comparative statics of decision-making under uncertainty.

${ }^{27}$ Ehrlich and Becker (1972).

${ }^{28}$ Chiu (2005); Eeckhoudt and Gollier (2005).

${ }^{29}$ Lee (2010).
} 
for insurance decision remain valid for self-insurance, because the productivity of self-insurance depends on the self-insurance technologies and the nature of the losses. An increase in self-insurance does not necessarily increase final wealth in the bad states or decrease final wealth in the good states, and self-insurance may not act as insurance. As a consequence, self-insurance is not necessarily inferior, even under DARA.

\section{More on adverse selection}

The insured is assumed to either have information that is relevant to the contract but that is unknown to the insurer (adverse selection) or to be able to perform some relevant action that is hidden to the insurer (moral hazard). LeRoy and Singell ${ }^{8}$ claimed that Knight brilliantly anticipated the literature on the failure of markets as a result of adverse selection and moral hazard. The distinction is not simply between insurable and uninsurable cases; rather Knight explicitly relied on asymmetric information in explaining why insurance is impossible in specific situations. Today, in economics and contract theory applied to insurance, most papers assume some form of asymmetric information.

Theoretical models predict that both adverse selection and moral hazard in insurance markets may generate inefficient outcomes. Theories of adverse selection and moral hazard also predict the occurrence of the risk and the coverage of the insurance should be positively correlated, whereas empirical researches find little support of it. There are various reasons why a coverage - risk correlation may not be found in some markets or pools of insurance policies. ${ }^{30}$ The paper by Huang et al. ${ }^{31}$ provides a theoretical model of hidden overconfidence and demonstrates that a competitive insurance market may settle on separating equilibrium with advantageous selection predicting a negative relationship between risk and coverage.

The paper parallels De Meza and Webb's setting, ${ }^{32}$ which includes both hidden information and hidden action. De Meza and Webb assume that there are two types of individuals, the timid (risk-averse) type and the bold (risk-neutral) type. The insurer cannot observe the hidden risk preferences of the insured and provides a product menu to screen the insured. In their paper, Huang et al. investigate the competitive market equilibrium under hidden overconfidence. Specifically, the concept of overconfidence is defined as the overly optimistic estimation of the probability of good future events by some agents. The presence of overconfidence is a phenomenon that is becoming increasingly significant and influential in behavioural finance. However, there is little discussion on how overconfidence influences insurance decision-making under asymmetric information when the insurer cannot figure out which agent is overconfident.

The mechanism of this separating equilibrium is the same as that in Rothschild and Stiglitz. ${ }^{33}$ The high risk type in Rothschild and Stiglitz's model is the overconfident

\footnotetext{
${ }^{30}$ Cohen and Siegelman (2010) review the literature on adverse selection in insurance markets.

${ }^{31}$ Huang et al. (2010).

${ }^{32}$ De Meza and Webb (2001).

${ }^{33}$ Rothschild and Stiglitz (1976).
} 
type in their model, and the low risk type is rational type. Contrary to the findings in Rothschild and Stiglitz, they show that, in equilibrium, rational individuals will invest in self-protection (low risk) and will purchase high coverage, whereas overconfident individuals will not invest in self-protection (high risk) and will purchase low coverage. The market settles on "advantageous selection", similar to the explanation given by De Meza and Webb.

The authors also show the case where both types of insured choose not to make any effort in equilibrium. In this case, the market has only one risk type rather than two risk types. However, overconfident individuals will purchase less insurance than rational individuals, as they are optimistic. This separating equilibrium does not separate risk type, but it does separate hidden overconfidence, which will be revealed by self-selection. The empirical implications of this case differ from those of De Meza and Webb. As both types of individuals have the same loss probability and are charged the same premium rate, the occurrence of the loss and the insurance coverage will be uncorrelated.

The classification of risks has always be a major preoccupation of insurers. Going back to Knight, he recognised the problem of defining groups as accurately as possible to increase the accuracy of statistical probability. Knight of course could not anticipate the depth of the regulatory state or the extension of institutionalised practices. Insurers' ability to determine risk categories, premiums and quantities are often limited by rating regulations. Such restrictions reduce the possibilities for sorting or selecting consumers through contract offerings, and make it difficult for low-risk consumers to avoid paying premium overcharges. The potential distortions to insurance markets and the associated efficiency losses from insurance rating restrictions have been well documented theoretically and empirically. The paper by Sharon Tennyson ${ }^{34}$ proposes an interesting summary of theoretical issues and empirical evidence in insurance markets.

There are market circumstances in which premium cross-subsidies from low risks to high risks represent an improvement because subsidised agents may be willing to purchase more insurance than under competitive pricing. This is the case if uninsures, impose negative externalities on other market participants. On the other hand, overcharged agents may purchase less insurance than is socially desirable. In health insurance, for example, insurers are required to charge the same premium to all consumers in the insured population, eliminating both underwriting and experience rating from the pricing system. This is defined as a pure community rating system. In automobile insurance, rating restrictions may impose premium equality across broad classes of consumers (classification by age, gender or marital status may be prohibited), but not across the entire population. As hypothesised by Tennyson, "if a sufficiently large proportion of high-risk drivers is uninsured, and if high-risk drivers make up a sufficiently small percentage of drivers, premium cross-subsidies from lowrisk to high-risk drivers can be Pareto improving. This type of reasoning may provide a theoretical justification for insurance rate cross-subsidies". ${ }^{35}$

\footnotetext{
34 Tennyson (2010).

${ }^{35}$ Tennyson (2010, p. 22).
} 
The paper develops the hypothesis that premium cross-subsidies affect risk-taking by insurance consumers and then examines the marginal effects of premium crosssubsidies on the risk-taking behaviour of subsidised and overcharged drivers in an automobile insurance market. Data from the regulated Massachusetts automobile insurance market is used for the time period 1990-2003 and for those interested, insurance regulation is explained in details. Subsidised drivers have reduced incentives to drive safely, and drivers who pay premium overcharges have increased incentives to drive safely. In other words, premium subsidies increase insurance costs, and premium overcharges decrease insurance costs. These findings are robust to several tests including controlling for time effects.

\section{The effect of constraints on contract design and market stability}

Value-at-Risk (VaR) has emerged as the standard tool for measuring financial risks and the past decade has witnessed a surge in the effort that financial market participants devote to risk management. ${ }^{36}$ The recent global financial crisis lead to serious concerns on the adequacy of VaR methodology to deal with credit risk. The paper by Bernard and $\operatorname{Tian}^{37}$ reveals some negative aspects of the regulatory VaR methodology in the insurance market. VaR measures the worst expected loss under normal market conditions over a specific time interval at a given confidence level.

In previous volumes of GRIR, papers have looked at the insured's VaR constraint into the optimal insurance decision. ${ }^{38}$ The paper by Bernard and Tian extends the classical analysis on optimal insurance design to the case when the insurer implements regulatory requirements (VaR). Presumably, regulators impose some risk management requirement such as $\mathrm{VaR}$ to reduce the insurers' insolvency risk, as well as to improve the insurance market stability. They show that $\mathrm{VaR}$ requirements better protect the insured in the event of large losses, but have negative effects on the insurance market because the insurer covers more and the default risk of the insurer is increased, as well as the instability of the market.

In another paper dealing with pension fund design, Kryger $^{39}$ considers optimal portfolio insurance for a mutually owned with-profits pension fund. Subsidies in this context may also exist between generations because the profits earned by the fund (the bonus) do not belong to a specific cohort of the population covered. Hence, in the short run, the fund (through the board) may accept that clients are not treated equally or alternatively, the demand for intergenerational fairness may come from some higher authority (the State for example). Assuming that it is desirable to obtain fairness, the author looks at investment strategies with regard to the bonus reserve and shows that even risk neutral clients would prefer modestly aggressive investment strategies for the fund.

\footnotetext{
${ }^{36}$ For a comprehensive history of the VaR concept, see Pradier (2005).

37 Bernard and Tian (2010).

${ }^{38}$ See Outreville (2010).

${ }^{39}$ Kryger (2010).
} 


\section{Discussion}

Among the papers published in this volume of the $G R I R$, some provide direct insights to the insurance industry by looking at the classification of risks and for example, the effect of cross-subsidies on the risk-taking behaviour of subsidised and overcharged policyholders. The classification of risks is a major preoccupation of insurers and it has implications on the determination of a separating equilibrium in a competitive market between high-risk and low-risk classes of individuals. Several papers touch upon the anomalies that can influence the performance of insurance markets. Insurance rating restrictions are often associated with potential distortions in insurance markets.

The issue of adverse selection, asymmetric information and moral hazard has also been examined in some papers and is of particular relevance for insurers and the proper functioning of insurance markets. Determinants of risk attitudes of individuals are also of great interest. Available empirical evidence suggests that the distribution of losses plays an important role in understanding the preferences of individuals and when risk and uncertainty or incomplete information about an alternative is introduced, people or organisations may behave somewhat different from rationality. Two papers illustrate this point by looking at the relationship between prudence, decreasing risk aversion and self-protection and giving examples in the understanding of individuals' betting behaviour and self-protection decisions.

\section{Conclusion}

This paper has summarised the papers published in the GRIR in 2010 (Volume 35). The publication of the 2009 Geneva Risk Economics Lecture in Bergen, given by Agnar Sandmo, ${ }^{11}$ is the starting point of this presentation. Historical reference to Willet and Knight is emphasised to illustrate the importance of risk and uncertainty in our modern economies and how it is still the starting point of economic research not only in public finance as proposed by Sandmo, but also in other papers published in this volume.

The Geneva Association, through publications like the GRIR, serves as a catalyst for progress in the understanding of risk and uncertainty applied to insurance matters. Asymmetric information, adverse selection and moral hazard are the keywords in several papers. These papers highlight how applied research in insurance could help understand the behaviour of policyholders and have important implications for the insurance industry.

\section{Acknowledgements}

The author thanks ICER in Turin (Italy) where he was visiting while he was writing this paper.

\section{References}

Arrow, K.J. (1965) Aspects of the Theory of Risk-Bearing, Helsinki: Hahnsson Foundation. 
Bernard, C. and Tian, W. (2010) 'Insurance market effects of risk management metrics', The Geneva Risk and Insurance Review 35(1): 47-80.

Bernstein, P.L. (1998) Against the Gods, The Remarkable Story of Risk, New York: John Wiley and Sons.

Bertrand, P. and Prigent, J.-L. (2010) 'A note on risk aversion, prudence and portfolio insurance', The Geneva Risk and Insurance Review 35(1): 81-92.

Borch, K. (1990) Economics of Insurance, Amsterdam: North-Holland Publishing Co.

Brooke, G.F. (2010) 'Uncertainty, profit and entrepreneurial action: Frank Knight's contribution reconsidered', Journal of the History of Economic Thought 32(2): 221-235.

Chiu, W.H. (2005) 'Skewness preference, risk aversion, and the precedence relations on stochastic changes', Management Science 51(12): 1816-1828.

Chiu, W.H. (2010) 'Skewness preference, risk taking and expected utility maximisation', The Geneva Risk and Insurance Review 35(2): 108-129.

Cohen, A. and Siegelman, P. (2010) 'Testing for adverse selection in insurance markets', Journal of Risk and Insurance 77(1): 39-84.

De Meza, D. and Webb, D.C. (2001) 'Advantageous selection in insurance markets', The Rand Journal of Economics 32(2): 249-262.

Domar, E.D. and Musgrave, R.A. (1944) 'Proportional income taxation and risk-taking', Quarterly Journal of Economics 58(3): 388-422.

Eeckhoudt, L. and Gollier, C. (2005) 'The impact of prudence on optimal prevention', Economic Theory 26(4): 989-994.

Eeckhoudt, L. and Schlesinger, H. (1994) ‘A precautionary tale of risk aversion and prudence', in B. Munier and M.J. Machina (eds.) Models and Experiments in Risk and Rationality, Dordrecht: Kluwer Academic Publishers.

Eeckhoudt, L. and Schlesinger, H. (2006) 'Putting risk in its proper place', American Economic Review 96(1): 280-289.

Eeckhoudt, L., Gollier, C. and Schneider, T. (1995) 'Risk-aversion, prudence and temperance: A unified approach', Economics Letters 48(3-4): 331-336.

Eeckhoudt, L., Gollier, C. and Schlesinger, H. (2005) Economic and Financial Decisions Under Risk, Princeton, NJ: Princeton University Press.

Ehrlich, I. and Becker, G.S. (1972) 'Market insurance, self-insurance and self-protection', Journal of Political Economy 80(4): 623-648.

Ericson, R.V. and Doyle, A. (2004) Uncertain Business: Risk, Insurance and the Limits of Knowledge, Toronto, Ontario: University of Toronto Press.

Huang, J. (2000) Relationships between risk aversion, prudence, and cautiousness, working paper 2000/022, Lancaster University Management School.

Huang, R.J., Liu, Y.J. and Tzeng, L.Y. (2010) 'Hidden overconfidence and advantageous selection', The Geneva Risk and Insurance Review 35(2): 93-107.

Holton, G.A. (2004) 'Defining risk', Financial Analysts Journal 60(6): 19-25.

Kimball, M.S. (1990) 'Precautionary saving in the small and in the large', Econometrica 58(1): 53-73.

Knight, F.H. (1921) Risk, Uncertainty and Profit, New York: Harper.

Knight, F.H. (1935) The Ethics of Competition and Other Essays, New York: Harper \& Brothers; London: George Allen \& Unwin.

Kryger, E.M. (2010) 'Pension fund design under long-term fairness constraints', The Geneva Risk and Insurance Review 35(2): 130-159.

Lajeria, F. and Nielsen, L.T. (2000) 'Parametric characterizations of risk aversion and prudence', Economic Theory 15: 469-476.

Lee, K. (2010) 'Wealth effects on self-insurance', The Geneva Risk and Insurance Review 35(2): 160-171.

Leland, H.E. (1980) 'Who should buy portfolio insurance?' Journal of Finance 35(2): 581-594.

LeRoy, S.F. and Singell, L.D. Jr. (1987) 'Knight on risk and uncertainty', The Journal of Political Economy 95(2): 394-406.

Menezes, C., Geiss, C. and Tressler, J. (1980) 'Increasing downside risk', American Economic Review 70(5): 921-932.

Outreville, J-F. (1998) Theory and Practice of Insurance, Boston, MA: Kluwer Academic Publishers. 
Outreville, J-F. (2010) 'The Geneva Risk and Insurance Review 2009: In quest of behavioural insurance', The Geneva Papers on Risk and Insurance - Issues and Practice 35(3): 484-497.

Pradier, P.-C. (2005) Value-at-risk since 1784: A comprehensive history, working paper, from http://www .univ-orleans.fr/deg/GDRecomofi/Activ/pradier_strasbg05.pdf.

Pratt, J.W. (1964) 'Risk aversion in the small and in the large', Econometrica 32(1-2): 122-136.

Rakow, T. (2010) 'Risk, uncertainty and prophet: The psychological insights of Frank H. Knight', Judgment and Decision Making 5(6): 458-466.

Rothschild, M. and Stiglitz, J.E. (1976) 'Equilibrium in competitive insurance markets: An essay on the economics of imperfect information', The Quarterly Journal of Economics 90(4): 629-649.

Sandmo, A. (2010) 'Uncertainty in the theory of public finance', The Geneva Risk and Insurance Review 35(1): 1-18.

Tennyson, S. (2010) 'Incentive effects of community rating in insurance markets: Evidence from Massachusetts automobile insurance', The Geneva Risk and Insurance Review 35(1): 19-46.

Willett, A.H. (1901) The Economic Theory of Risk and Insurance, New York: Columbia University Press, Reedited in 1951 by the University of Pennsylvania Press.

\section{About the Author}

Jean-François Outreville is Adjunct Professor of Risk Management and Insurance in the Department of Finance at HEC Montreal in Canada. He is also Research Fellow at ICER-Turin (Italy). 